Л.Д. Демидова*

Плагиат как способ сохранения научного результата: неожиданный сюжет из истории дореволюционного изучения русского старообрядчества

DOI: 10.31518/2618-9100-2019-6-11

УДК 94(48).08

Выходные данные для цитирования:

Демидова Л.Д. Плагиат как способ сохранения научного результата: неожиданный сюжет из истории дореволюционного изучения русского старообрядчества // Исторический курьер. 2019. № 6 (8). C. 129-136. URL: http://istkurier.ru/data/ 2019/ISTKURIER-2019-6-11.pdf
L.D. Demidova*

\section{Plagiarism as a Way of Preserving a Scientific Result: an Unexpected Case from the History of Pre-Revolutionary Study of the Russian Old Believers}

DOI: $10.31518 / 2618-9100-2019-6-11$

How to cite:

Demidova L.D. Plagiarism as a Way of Preserving a Scientific Result: an Unexpected Case from the History of Pre-Revolutionary Study of the Russian Old Believers // Historical Courier, 2019, No 6 (8). P. 129-136. [Available online:] http:// istkurier.ru/data/2019/ISTKURIER-2019-6-11.pdf

Abstract. A small story discovered while studying historiography of the $17^{\text {th }}$ century Russian church schism and of the Old Believers appeared strikingly vital in the epoch of hunt for scientific citations and fight against "improper borrowings" of scientific texts. It is on the article published at 1914 that the currently circulating information is largely based that concerns biography of the monk Avraamii (burned in 1672) - the former holy fool Athanasius, an Old Believer polemic writer, contemporary and follower of Archpriest Avvakum. At the closer examination this artilce, the most extensive and detailed of all ever written biographies of Avraamii, appeared to be a plagiary. Its author, a student of the Kiev Theological Academy, N. Demin, borrowed the text from the work of 1895 written by P. Dobromyslov, editor of the journal "Missionary Collection". It seems to be a matter of chance that researchers who revived the tradition of the Old Belief studies at the second half of the $20^{\text {th }}$ century became acquainted to the plagiary while the robbed text was left unnoticed aside from the scientific discussion. The case has been complicated additionally by the two decades' chronological gap between the original work and the plagiary, during which researchers found some new documents concerning Avraamii. Taking into consideration these documents, the plagiary author N. Demin offered several hypotheses that laid foundation for a later hypothesis concerning motives of the Avraamii's taking monastic vows. However, the dishonest deed of the Kiev student was not the only cause for the original article of P. Dobromyslov being forgotten. Rather, the main reason for that was ignoring Dobromyslov's article by a recognized pre-revolutionary classic of the Old Belief studies P.S. Smirnov. This circumstance is hard to explain, since Smirnov, the author of the fundamental work "Internal Issues in the Schism in the $17^{\text {th }}$ Century" (1898), and of a biographical article about Avraamii, very probably was personally acquainted with P. Dobromyslov. To sum up, the investigation of this case discovered a paradoxical story of a research that did not enter the scientific canon, but its result, thanks to the improper borrowing, was not lost for science.

Keywords: $17^{\text {th }}$ century Russian church schism; Old Believers; monk Avraamii; improper borrowing in science.

The article has been received by the editor on 02.11.2019.

Full text of the article in Russian and references in English are available below.

\footnotetext{
* Демидова Лариса Денисовна, кандидат исторических наук, независимый исследователь (Новосибирск, Россия), e-mail: lardem.nsk@gmail.com

Demidova Larisa D., Candidate of Historical Sciences, independent researcher (Novosibirsk, Russia), e-mail: lardem.nsk@gmail.com
} 
Аннотация. Частный сюжет из истории изучения церковного раскола XVII в. и старообрядчества оказался неожиданно актуальным в эпоху погони за научной цитируемостью и борьбы с некорректными заимствованиями. Ныне известные сведения о биографии инока Авраамия (сожжен в 1672 г.), бывшего юродивого Афанасия, старообрядческого писателяполемиста, современника и последователя протопопа Аввакума, во многом базируются на статье, опубликованной в 1914 г. Эта самая обширная и подробная из всех когда-либо написанных биографий Авраамия при ближайшем рассмотрении оказалась плагиатом. Ее автор, слушатель Киевской духовной академии Н. Дёмин позаимствовал текст из работы 1895 г., написанной П. Добромысловым, редактором журнала «Миссионерский сборник». Видимо, по чистой случайности, исследователям II половины XX в. стал известен плагиат, в то время как оригинальная статья оставалась до сих пор незамеченной и не введенной в научный оборот. Кроме того, поскольку за два десятилетия, отделяющие оригинальную статью от заимствования, были найдены немногочисленные новые документы об Авраамии, Н. Дёмин сделал на основе них несколько предположений, которые впоследствии легли в основу гипотезы о мотивах монашеского пострига старообрядца. Предполагаемой причиной того, что оригинальная статья П. Добромыслова долгое время была невостребованной, стал, однако, не столько недобросовестный поступок киевского студента, сколько полное игнорирование статьи П. Добромыслова П.С. Смирновым. Это обстоятельство труднообъяснимо, поскольку признанный дореволюционный классик изучения старообрядчества, автор фундаментального труда «Внутренние вопросы в расколе в XVII в.» (1898 г.) и биографической статьи об иноке с большой долей вероятности был лично знаком с П. Добромысловым. Работа 1895 г. не попала в научный канон, тем не менее, ее результат, благодаря некорректному заимствованию, не пропал для науки бесследно.

Ключевые слова: церковный раскол XVII в.; старообрядчество; инок Авраамий; некорректное заимствование в науке.

Занятие наукой в наши дни, особенно оформленное институционально, с некоторых пор немыслимо без подсчета показателей цитируемости. Давняя традиция ссылок на предшественников, возникнув одновременно с появлением научного знания в современном виде и некогда призванная обеспечивать его преемственность, сегодня стала способом оценки качества публикации и ценности ее автора ${ }^{1}$. Стремительный рост количества научных публикаций послужил причиной нередкого недоучета достижений предшественников: как непреднамеренного - из-за физической невозможности следить за возрастающим валом публикаций, так и преднамеренного, вызванного, в частности, желанием не повышать научному конкуренту индекс цитируемости ${ }^{2}$. Одновременно с этим громко заявила о себе проблема корректности цитирования, вызвавшая к жизни сообщество «Диссернет», а также обязательные проверки на антиплагиат квалификационных работ самого разного уровня. Разоблачения авторов недобросовестных кандидатских и докторских диссертаций сделали борьбу с плагиатом повесткой дня. В свете этого небольшой сюжет, встретившийся мне в процессе знакомства с историографией раннего старообрядчества, помимо академической актуальности, оказался неожиданно злободневен, показав заодно, какими неожиданными путями порой происходит сохранение и передача научного знания.

Жизнь и труды первого поколения борцов с церковной реформой 50-х гг. XVII в. считаются исследованными намного лучше, чем биографии и сочинения их многочисленных последователей, представителей разных толков и согласий. Однако при близком рассмотрении выясняется, что самым подробным образом изучен лишь жизненный путь протопопа Аввакума - он один может похвастаться целой «Летописью», составление

\footnotetext{
${ }^{1}$ Кистерев С.Н. Ссылки и сноски в российской историографии. М.; СПб., 2019. С. 11.

${ }^{2}$ Там же. С. 14-15, 26.
} 
которой стало делом жизни археографа Владимира Ивановича Малышева ${ }^{3}$. Даже о ближайшем окружении протопопа известно в разы меньше, чем о нем самом. Не стала исключением и биография инока Авраамия, бывшего юродивого Афанасия - полемиста и духовного сына Аввакума (сожжен в 1672 г.). Это связано исключительно с состоянием источников - до нас дошло незначительное их количество, а сведения, ими сообщаемые, чрезвычайно фрагментарны. С того самого момента, когда русская историческая наука заинтересовалась старообрядчеством, Авраамий, хоть и не удостоился отдельного, посвященного ему труда, вызывал у исследователей неизменный интерес как автор ярких сочинений, обличающих нововведения патриарха Никона. Однако за полтора столетия историки старообрядчества умудрились нагромоздить целый клубок догадок о его жизни, поскольку не всегда давали себе труд объяснить, на каких источниках основано то или иное утверждение и в какой степени оно достоверно.

Наиболее авторитетная и полная на сегодняшний день биографическая справка об Авраамии была написана Александром Михайловичем Панченко и Натальей Вячеславовной Савельевой для «Словаря книжников и книжности Древней Руси» ${ }^{4}$ Статья опирается на материал более ранних работ А.М. Панченко - «Русская стихотворная культура XVII в.» и «“Смеховой мир” Древней Руси». В этих работах исследователь попытался ответить на вопрос, какие мотивы побудили юродивого Афанасия около 1665-1667 гг. отказаться от «аскетики самоуничижения» и принять постриг под именем Авраамия. Он заметил, что именно с принятием монашества связано начало литературной деятельности Авраамия, смысл которой заключался в обличении реформ патриарха Никона и защите старого обряда: необходимость обличать диктовала необходимость писать, необходимость писать - оставить образ жизни юродивого, поскольку, как предположил исследователь, юродство и писательство являлись вещами несовместимыми (для обоснования этого предположения A.М. Панченко прибегнул к аналогии, привлекая сведения о других известных юродивых $)^{5}$. Объяснение выглядит убедительным: действительно, от юродивого Афанасия не сохранилось ни строчки, в то время как от инока Авраамия дошло свыше десятка сочинений в защиту старого обряда, в том числе два весьма значительных - сборник «Христианоопасный щит веры против еретического ополчения» и Челобитная царю Алексею Михайловичу 1670 г. Выстраивая свою гипотезу, А.М. Панченко указал, что сведения о жизни Авраамия он почерпнул из статьи некоего Николая Дёмина «Расколоучитель старец Авраамий», вышедшей в Киеве в 1914 году ${ }^{6}$ С легкой руки исследователя это название попало в несколько работ, в числе которых специализированный справочник ${ }^{7}$, причем все известные мне ссылки на статью Н. Дёмина содержат ошибку в библиографическом описании, почерпнутую именно из исследований А.М. Панченко: дело в том, что сборник, в котором она опубликована, имеет название не «Учебно-богословские...», а «Учёно-богословские и церковно-проповеднические опыты студентов Киевской духовной академии».

Статья Н. Дёмина является самой обширной и подробной из всех когда-либо написанных биографий Авраамия, несмотря на то, что представляет собой курсовое сочинение слушателя Киевской духовной академии (как об этом сообщает ремарка в самой статье и название сборника). Студенческая работа 1914 года приятно поражает: она выполнена по строгим научным стандартам своего времени, учащегося в авторе выдает лишь кое-где излишняя велеречивость слога, и быть может, чересчур подробный пересказ предшественников. Предшественники досконально перечислены в историографическом обзоре в начале

\footnotetext{
${ }^{3}$ Малышев В.И. Материалы к «Летописи жизни протопопа Аввакума» // Древнерусская книжность: По материалам Пушкин. Дома: Сб. науч. тр. М.-Л., 1954. С. 277-322.

${ }^{4}$ Панченко А.М., Шухтина (Савельева) Н.В. Авраамий // Словарь книжников и книжности Древней Руси. Вып. 3 (XVII в.). Часть 1. СПб., 1992. С. 31.

${ }^{5}$ Панченко А.М. Русская стихотворная культура XVII в. Л., 1973. С. 91.

${ }^{6}$ Демин Н. Расколоучитель старец Авраамий // Учено-богословские и церковно-проповеднические опыты студентов Киевской духовной академии... Вып. 12 : ... LXVII курса (1914 г.). Киев, 1914. С. 124-232.

${ }^{7}$ Старообрядчество: история и культура: библиографический указатель: книги и статьи на русском и иностранных языках (1900-2009). М., 2011. С. 86 (№ 1163).
} 
статьи, показаны их заслуги, ошибки и заблуждения. Вне всякого сомнения, и источники, и предшественников Н. Дёмин знал великолепно - за одним исключением: полностью проигнорирована магистерская диссертация Петра Семеновича Смирнова «Внутренние вопросы в расколе в XVII веке» (1898 г.) - ставший ныне классикой труд по истории раннего старообрядчества. Зато имеется название, упоминания о котором нет в известных мне работах об Авраамии: П. Добромыслов, «Расколоучитель старец Авраамий и его значение в истории раскола», статья 1895 г. ${ }^{8}$ Ссылки на эту статью расставлены в сочинении Н. Дёмина регулярно, хотя в историографическом обзоре он обошел ее полным молчанием. Кроме того, неясен сам характер цитирования статьи: из изложения Н. Демина следует, что на П. Добромыслова он ссылается, в основном, чтобы подкрепить свои собственные тезисы, но какое-либо содержательное обсуждение позиции последнего по тому или иному вопросу отсутствует.

Объяснение странностям работы Н. Дёмина нашлось после знакомства со статьей П. Добромыслова и оказалось до чрезвычайности банальным: Н. Дёмин в лучших школярских традициях позаимствовал у П. Добромыслова его текст, причем в той части сочинения, где речь идет о биографии Авраамия - почти полностью. Правильным будет привести пару характерных примеров такого заимствования:

\section{П. Добромыслов.}

Расколоучитель старец Авраамий и его значение в истории раскола // Миссионерский сборник

1895. № 1. С. 20: В науке истории нередко бывают случаи, когда ученые исследователи, основываясь на чисто внешних и случайных данных, отождествляют двух совершенно различных исторических деятелей, современных друг другу; такие ошибки возможны бывают, конечно, в тех случаях, когда под руками исследователей не имеется достаточных данных для точного определения известной личности. Такую именно ошибку встречаем мы при решении вопроса о том: кто был Авраамий - автор известной Челобитной к царю Алексею Михайловичу?

1895. № 2. С. 134: Сторонники сосланных Никоном расколоучителей, вроде юродивого Афанасия, открыли против патриарха ту подпольную, глухую войну, которая не стесняется в выборе средств и в большинстве случаев выражается в тайных подстрекательствах народной массы, в разжигании страстей и в самых беззастенчевых клеветах, и, как таковая, совсем не поддается строгому историческому анализу.

\section{Н. Дёмин.}

Расколоучитель старец Авраамий // Ученобогословские и церковно-проповеднические опыты студентов Киевской духовной академии... Вып. 12 : ... LXVII курса (1914 г.). Киев, 1914.

С. 124: Исследователю жизни и деятельности расколоучителя старца Авраамия прежде всего приходится сталкиваться с вопросом о том: кто был Авраамий - автор известной Челобитной царю Алексею Михайловичу? Вопрос этот очень спорный и до самого последнего времени решался он нашими историками различно. Этого Авраамия отождествляли со многими другими личностями, которые как-либо известны в истории раскола. Подобные исторические ошибки происходили, конечно, оттого, что исследователи, не имея достаточных данных для точного определения этой личности, основывались на чисто внешних $и$ случайных данных, результатом чего и было отождествление двух совершенно различных исторических деятелей, современных друг другу.

С. 142: Впрочем, о деятельности Афанасия в указанный период времени ничего определенного сказать нельзя, как как [очевидно: так как - Л.Д.] вообще сторонники сосланных расколоучителей, сознавая свое бессилие вести открытую борьбу с влиятельным патриархом, открыли теперь против него тайную, подпольную компанию [так! - Л.Д.], которая не поддается строгому историческому анализу.

Аккуратные, кое-где не без изящества, изменения словесных формулировок позволили Н. Дёмину избежать дословного совпадения фраз и выражений. Если при чтении не заглядывать параллельно в статью П. Добромыслова, создается иллюзия полной правдоподобности дотошно проделанной научной работы, в которой даже сноски близки к совершенству:

\footnotetext{
${ }^{8}$ Добромыслов П. Расколоучитель инок Авраамий и его значение в истории раскола // Миссионерский сборник. 1895. № 1. С. 15-29, № 2. 125-141, № 3. С. 199-211, № 4. С. 276-292, № 5. С. 409-421, № 6. С. $473-487$.
} 


\section{П. Добромыслов.}

Расколоучитель старец Авраамий и его значение в истории раскола // Миссионерский сборник. 1895. №. 1. C. 28.

Сноска 1: На листе 65 рукоп[иси] Имп[ераторской] Публич[ной] библ[иотеки] приведенное место читается иначе: «у великаго и предивнаго отца Иосифа Ламенскаго». Кого разумеет С. Денисов под Иосифом Ламенским или Ламским? Можно думать, что и в том и в другом случае разумеется Иосифо-Волоколамский монастырь, находящийся теперь в пределах Новгородской епархии, а в первое время по основании (1478 г.) числившийся за Москвой. Высказывать такое предположение дает право то обстоятельство, что Волоколамск назывался иногда Ламском; так, в Никоновой летописи (ч. VI, стр. 106) при описании основания Иосифо-Волоколамского монастыря говорится: «Иосиф старец начал строчти монастырь на Ламском Волоце в пустыне». (Смотр. об этом монастыре «Историю российской иерархии» - m. III, M. 1811 г., стр. 602-607 и VI, 2. М. 1815 г., стр. 974-976. Очевидно, пленившись громкой славой Иосифо-Волоколамского монастыря, Афанасий из Нижегородских пределов перешел в Новгородские.

\section{Н. Дёмин.}

Расколоучитель старец Авраамий // Ученобогословские и церковно-проповеднические опыты студентов Киевской духовной академии... Вып. 12 : ... LXVII курса (1914 г.). Киев, 1914. C. 134-135.

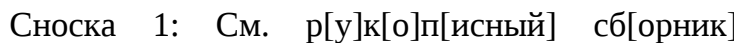
наш[ей] биб[лиотеки] № Аа 135, «Вин[оград] Росс[ийский]» л. 57 об. Можно думать, что С. Денисов разумеет здесь Иосифо-Волоколамский монастырь, находящийся теперь в пределах Новгородской епархии, а в первое время по основании (1478 г.) числившийся за Москвой. В пользу такого предположения говорит то обстоятельство, что Волоколамск назывался иногда Ламском: напр., Никонова летопись (ч. VI, стр. 106) об основании Иосифо-Волоколамского монастыря говорит: «Иосиф старец начал строити монастырь на Ламском Волоце в пустыне». Этими замечаниями о монастыре мы здесь и ограничимся, а более подробную историю его можно читать в «Истории росс[ийской] иерархии» арх. Амвросия, ч. III, М. 1811 г., стр. 602-607 и ч. VI, 2. M. 1815 г., стр. 974-976. Очевидно, пленившись громкой славой Иосифо-Волоколамского монастыря, Афанасий из Нижегородских пределов перешел в Новгородские.

Можно даже думать, что Н. Дёмин приложил некоторые усилия для самостоятельного знакомства с источниками: в ссылке на рукопись «Винограда Российского», известного старообрядческого мартиролога XVIII в. (в нем содержится жизнеописание Авраамия - один из источников сведений о нем), киевский студент указал экземпляр, который, по-видимому, мог быть ему действительно доступен. П. Добромыслов ссылается на рукопись «Винограда» из коллекции Императорской Публичной библиотеки, Н. Дёмин - на книгу из собрания Киевской духовной академии. Цитата из «Винограда», которой открывается сноска у П. Добромыслова («у великого и предивнаго отца Иосифа Ламенскаго»), у Н. Дёмина перемещена из сноски в основной текст, чем объясняется ее отсутствие в приведенном примере.

Итак, самостоятельностью сочинение киевского студента обладало в минимальной степени. Именно фактом заимствования объясняется игнорирование Н. Дёминым «Внутренних вопросов в расколе» П.С. Смирнова, ведь когда П. Добромыслов в 1895 г. писал свою статью, до выхода их в свет оставалось еще три года.

Справедливости ради нужно отметить, что Н. Дёмин, хотя и не афишировал основной источник своего сочинения, но и не стремился сокрыть его полностью, что и помогло в итоге найти оригинальное исследование. Кроме того, поскольку за неполные два десятка лет, разделяющие оригинальную статью и студенческое сочинение, изучение старообрядчества не стояло на месте, Н. Дёмину удалось сделать и собственные дополнения к умозаключениям П. Добромыслова. Несмотря на то, что магистерская диссертация П.С. Смирнова так и осталась для воспитанника духовной школы неизвестной, научные выводы автора «Внутренних вопросов» все-таки проникли в реферат, хоть и окольным путем. Дело в том, что в 1912 г. историк Яков Лазаревич Барсков выпустил свои «Памятники первых лет старообрядчества», которые содержали вновь найденные документы об Авраамии. О существовании публикации киевский студент оказался осведомлен и сообщения документов принял к сведению. В примечаниях к «Памятникам» была указана дата смерти Авраамия и изложено обоснование - со ссылкой на П.С. Смирнова, который первый предпринял попытку ее 
установить. Эту аргументацию и переписал Н. Дёмин, поскольку статья П. Добромыслова оставляла вопрос открытым. Кроме того, на основании опубликованных документов Н. Дёмин выдвинул предположение о возможном времени пострига Авраамия и обстоятельствах, этому сопутствовавших: бывший юродивый принял монашество, бежав из столицы в 1665 г., когда старообрядческих вождей постигли гонения, и вернулся туда через два года - в 1667 г. Опираясь на это предположение, А.М. Панченко впоследствии вывел свою гипотезу о побудительных мотивах этого шага: отъезд юродивого был осмыслен исследователем как совершенно сознательный выбор человека, решившего сжечь все мосты и всецело посвятить себя борьбе за старый обряд в тяжелейших для его защитников условиях.

Курсовое сочинение Н. Дёмина, таким образом, можно рассматривать как реферат, в котором нашли отражение самые свежие на момент его написания научные сведения о жизни Авраамия. Возможно, слушатель академии и не претендовал на нечто большее, отчего, тем не менее, его сочинение быть плагиатом не перестает: он довольно бесцеремонно заимствовал и мысли П. Добромыслова, и структуру его текста, и сам текст.

Почему же получилось так, что работа, которая при нормальных условиях функционирования науки должна была быть заклеймена за воровство и забыта, оказалась востребованной, в то время как статью П. Добромыслова постигло совершенно незаслуженное забвение? Это при том, что проигнорированная наукой статья была опубликована в куда более известном и авторитетном периодическом издании, нежели собрание студенческих «опытов» Киевской духовной академии. Журнал «Миссионерский сборник», возникший как приложение к Рязанским епархиальным ведомостям, позиционировался как издание, специально ориентированное на борьбу с расколом и сектантством. Значит, искать исследования о «расколоучителях» (так православные миссионеры XIX в. именовали старообрядческих идейных лидеров) в первую очередь логично было бы именно в нем. Сложившийся парадокс отчасти объясним историческими обстоятельствами, в которых некогда велись старообрядческие исследования. Следствием их искусственного прекращения, наступившего в начале второго десятилетия XX в. и продолжавшегося вплоть до 50-60-х гг., ожидаемо стал и разрыв научной традиции. Новое поколение исследователей старообрядчества не только должно было позиционировать себя в качестве борцов с дореволюционной «буржуазной наукой», но и оказалось ни институционально, ни лично не связанным с учеными, которые некогда задавали тон в изучении раскола и впоследствии были отнесены к т. н. «синодальному направлению» в историографии. В этих условиях непростой в доинтернетную эпоху поиск дореволюционной литературы об Авраамии обернулся, по-видимому, случайной находкой в виде сочинения Н. Дёмина. Предположительно, А.М. Панченко оно стало известно с подачи его старшего коллеги, исследователя литературы XVII в. - Андрея Николаевича Робинсона. Последний, в 1963 г. выпуская в свет «Жития» протопопа Аввакума и инока Епифания, написал об Авраамии краткую биографическую справку - первую в советской научной литературе 9 . Своих источников исследователь не назвал, они выясняются путем сопоставлений текста с научными результатами его предшественников. Часть сведений в этой справке с большой долей вероятности почерпнута именно из статьи Н. Дёмина, поскольку возникла как итог цепи логических допущений, сделанных при интерпретации источников именно П. Добромысловым, и затем позаимствованных у него киевским студентом: к примеру, утверждение о нижегородском происхождении Авраамия непременно вкупе с его юношескими скитаниями, замечание о посещении будущим иноком книгохранилищ Троице-Сергиева и Иосифо-Волоколамского монастырей.

Обнаружение сочинения $\mathrm{H}$. Дёмина не позволило бесследно пропасть научному результату П. Добромыслова. Однако оригинальная статья была проигнорирована не только более поздними исследователями, но и современниками ее автора. В нем логично видеть Петра Павловича Добромыслова (1866-?), выпускника Санкт-Петербургской духовной

\footnotetext{
${ }^{9}$ Робинсон А.Н. Жизнеописания Аввакума и Епифания. М., 1963. С. 275-276.
} 
академии (1890 г.), а в 1895-1902 гг. редактора «Миссионерского сборника» ${ }^{10}$. Если лицо установлено верно, П. Добромыслов просто не мог не быть лично знаком с П.С. Смирновым, поскольку именно из рук последнего в 1895 г. к П.П. Добромыслову перешло редактирование издания. Тем не менее, оба сохранили друг о друге полнейшее молчание. Именно отсутствие ссылок на статью П.П. Добромыслова в фундаментальных «Внутренних вопросах», по-видимому, оказалось для нее куда более неблагоприятным обстоятельством, чем недобросовестный поступок Н. Дёмина. Если бы не прицельный интерес к фигуре Авраамия, плагиат киевского студента мог оставаться неизвестным неопределенно долгое время, представить же изучение раннего старообрядчества в целом без книги П.С. Смирнова попросту невозможно. Были ли тому причиной личные взаимоотношения П.П. Добромыслова и П.С. Смирнова, либо расхождения в научных взглядах (опираясь на один и тот же круг источников, авторы по-разному подошли к их критике $\left.{ }^{11}\right)$, научный результат П. Добромыслова не стал со стороны П.С. Смирнова ни предметом критики, ни предметом обсуждения, а потому статья и не попала своевременно в научный канон.

\section{Лumepamypa}

Андреев Г.Л. Христианская периодическая печать на русском языке, 1801-1917 гг.: библиографический указатель. T. I. New York, 1998. 207 с.

Демин Н. Расколоучитель старец Авраамий // Учено-богословские и церковно-проповеднические опыты студентов Киевской духовной академии... Вып. 12 : ... LXVII курса (1914 г.). Киев, 1914. С. 124-232.

Добромыслов П. Расколоучитель инок Авраамий и его значение в истории раскола // Миссионерский сборник. 1895. № 1. С. 15-29, № 2. С. 125-141, № 3. С. 199-211, № 4. С. 276-292, № 5. С. 409-421, № 6. С. 473-487.

Кистерев С.Н. Ссылки и сноски в российской историографии. М.; СПб., 2019. 80 с.

Малышев В.И. Материалы к «Летописи жизни протопопа Аввакума»// Древнерусская книжность: По материалам Пушкин. Дома: Сб. науч. тр. М.-Л., 1954. С. 277-322.

Панченко А.М., Шухтина (Савельева) Н.В. Авраамий // Словарь книжников и книжности Древней Руси. Вып. 3 (XVII в.). Часть 1. СПб., 1992. С. 31-34.

Панченко А.М. Русская стихотворная культура XVII в. Л., 1973. 280 с.

Православная богословская энциклопедия. Т. 1. СПб., 1900. 584 с.

Робинсон А.Н. Жизнеописания Аввакума и Епифания. М., 1963. 316 с.

Старообрядчество: история и культура: библиографический указатель: книги и статьи на русском и иностранных языках (1900-2009). М., 2011. 461 с.

\section{References}

Andreev G.L. (1998). Hristianskaya periodicheskaya pechat' na russkom yazyke, 18011917 gg.: bibliograficheskij ukazatel. [Christian periodicals in Russian, 1801-1917: a bibliographical index]. New York. Vol. I. 207 p.

Demin N. (1914). Raskolouchitel starec Avraamij [The schismatic elder Avraamii]. In Uchyono-bogoslovskie i cerkovno-propovednicheskie opyty studentov Kievskoj duhovnoj akademii [Scientific-theological and church-preaching essays of students of the Kiev Theological Academy]... Issue. 12 : ... LXVII course (1914). Kiev. Pp. 124-232.

Dobromyslov P. (1895). Raskolouchitel inok Avraamij i ego znachenie $v$ istorii raskola [Schismatic monk Avraamii and his role in the history of the Schism]. In Missionerskij sbornik [Missionary collection]. № 1. P. 15-29, № 2. P. 125-141, № 3. P. 199-211, № 4. P. 276-292, № 5. P. 409-421, № 6. Pp. 473-487.

\footnotetext{
${ }^{10}$ Андреев Г.Л. Христианская периодическая печать на русском языке, 1801-1917 гг.: библиографический указатель. Т. I. New York, 1998. № 410.

${ }^{11}$ Помимо строк посвященных Авраамию во «Внутренних вопросах», П.С. Смирнов написал о нем специальную энциклопедическую статью: Православная богословская энциклопедия. СПб., 1900. Т. 1. Стб. $224-225$.
} 
Kisterev S.N. (2019). Ssylki i snoski v rossijskoj istoriografii [References and footnotes in Russian historiography]. Moscow; St.-Petersburg. 80 p.

Malyshev V.I. (1954). Materialy k "Letopisi zhizni protopopa Avvakuma" [Materials for the "Chronicle of the Life of Protopope Avvakum"]. In Drevnerusskaya knizhnost: Po materialam Pushkin. Doma [Old Russian Book in the materials of the Pushkin House]: collected articles. Moscow; Leningrad. Pp. 277-322.

Panchenko A.M., Shuhtina (Saveleva) N.V. (1992). Avraamij [Avraamii]. In Slovar knizhnikov i knizhnosti Drevnej Rusi [Dictionary of scribes and books of Ancient Russia]. St.-Petersburg. Vol. 3 (17th century). Part 1. Pp. 31-34.

Panchenko A.M. (1973). Russkaya stihotvornaya kultura XVII v. [Russian poetic culture of the $17^{\text {th }}$ century]. Leningrad. 280 p.

Pravoslavnaya bogoslovskaya enciklopediya. [Orthodox Theological Encyclopedia]. (1900). St.-Petersburg. Vol. 1. 584 p.

Robinson A.N. (1963). Zhizneopisaniya Avvakuma i Epifaniya [Biographies of Avvakum and Epifania]. Moscow. 316 p.

Staroobryadchestvo: istoriya i kultura: bibliograficheskij ukazatel: knigi i stat'i na russkom i inostrannyh yazykah (1900-2009) [Old Believers: history and culture: bibliography: books and articles in Russian and foreign languages (1900-2009)]. (2011). Moscow. 461 p.

Статья поступила в редакцию 02.11.2019 г. 